\title{
Pulmonary hypertension in pregnancy
}

\author{
K. Durga ${ }^{1}$, S. Yuvarajan ${ }^{2 *}$, R. Praveen ${ }^{2}$, Antonious Maria Selvam ${ }^{2}$, Yashoda $^{1}$, Karthiga V. $^{3}$
}

\author{
${ }^{1}$ Department of Obstetrics and Gynaecology, SLIMS, Pondicherry, India \\ ${ }^{2}$ Department of Respiratory Medicine, SMVMCH, Pondicherry, India \\ ${ }^{3}$ Government Kasturba Gandhi Hospital, Chennai, Tamil Nadu, India
}

Received: 29 November 2020

Revised: 20 January 2021

Accepted: 21 January 2021

\section{*Correspondence:}

Dr. S. Yuvarajan,

E-mail: nsivagnaname@yahoo.com

Copyright: $\odot$ the author(s), publisher and licensee Medip Academy. This is an open-access article distributed under the terms of the Creative Commons Attribution Non-Commercial License, which permits unrestricted non-commercial use, distribution, and reproduction in any medium, provided the original work is properly cited.

\section{ABSTRACT}

Pulmonary hypertension is defined as an increase in mean pulmonary arterial pressure (mPAP) $\geq 25 \mathrm{mmHg}$ at rest as assessed by right heart catheterisation. Pulmonary hypertension in pregnancy is known to be associated with significantly high morbidity and mortality rate which ranges between $30 \%$ and $56 \%$. So during pregnancy, efforts to be made to diagnose common medical ailments that can be complicated by pulmonary hypertension. Bedside 2D Echo and thoracic ultrasound are the strongly recommended in these patients to diagnose early and prevent the devastating complications. Relevant blood investigations need to be sent to diagnose the underlying etiology and to assess the prognosis. Cardiac catheterization is the gold standard investigation of choice for pulmonary hypertension. But it is 1 performed in very few cardiac centres in developing countries. In India diagnosis largely depends on echocardiography. It should be made clear to women at the time of their PAH diagnosis that pregnancy is not recommended due to the high maternal and fetal risks. If a woman with known PHT become pregnant, counselling should be given for therapeutic abortion. If they are willing for therapeutic abortion, it should be done before 22 weeks of gestation. All women with PHT should be initiated on PAH specific therapies (prostanoids, ccbs, phosphodiesterase inhibitors) except endothelin receptor blockers as it is teratogenic. Pregnancy in PAH is difficult to manage and needs mutidisciplanary team. Pregnancy is not recommended in women with PAH and appropriate counselling to be done to the mother and their relatives.

Keywords: Pregnancy, Pulmonary hypertension, Blood investigations

\section{INTRODUCTION}

Pulmonary arterial hypertension $(\mathrm{PAH})$ is a disease of the small pulmonary arteries characterised by vascular proliferation and remodelling leading to progressive increase in pulmonary vascular resistance, right venticular failure and sudden death. Pulmonary hypertension is defined as an increase in mean pulmonary arterial pressure $(\mathrm{mPAP}) \geq 25 \mathrm{mmHg}$ at rest as assessed by right heart catheterisation. ${ }^{1}$ Most commonly presents in women of childbearing age. Subclinical pulmonary arterial hypertension may be unmasked in pregnancy.
Pulmonary hypertension $(\mathrm{PH})$ in pregnancy is known to be associated with significant high morbidity and mortality rates which ranges between $30 \%$ and $56 \% .^{2-4}$ The physiological changes that occur during pregnancy and the peripartum period are poorly tolerated. So during pregnancy, efforts to be made to diagnose common medical ailments that can be complicated by pulmonary hypertension. These include pulmonary embolism either with thrombi or amniotic fluid which are relatively common and mostly fatal. Most of the maternal PHassociated deaths occur during labor or within 1-month post-partum. Clinical signs and symptoms are nonspecific 
and often missed in this stage. Echocardiogram and thoracic ultrasound are the strongly recommended in these patients to diagnose early and prevent the devastating complications. $^{2}$

\section{Physiological changes in pregnancy}

Various physiological changes occur during pregnancy which impact on the hemodynamic ramifications in PAH (Figure 1). Almost all systems are involved in this physiological drift. Blood volume may increase almost fifty percent above the non-pregnant level which in turn peaks during second and third trimester of pregnancy. ${ }^{5}$ There is significant increase in heart rate and stroke volume which in turns affects the cardiac output. ${ }^{6}$ During normal pregnancy there is a fall in both systemic and pulmonary vascular resistance because of predominant vasodilation. However, in patients with PHT, pulmonary vasculopathy heralds the fall of PVR leads to further rise in Pulmonary pressures with increased cardiac output.

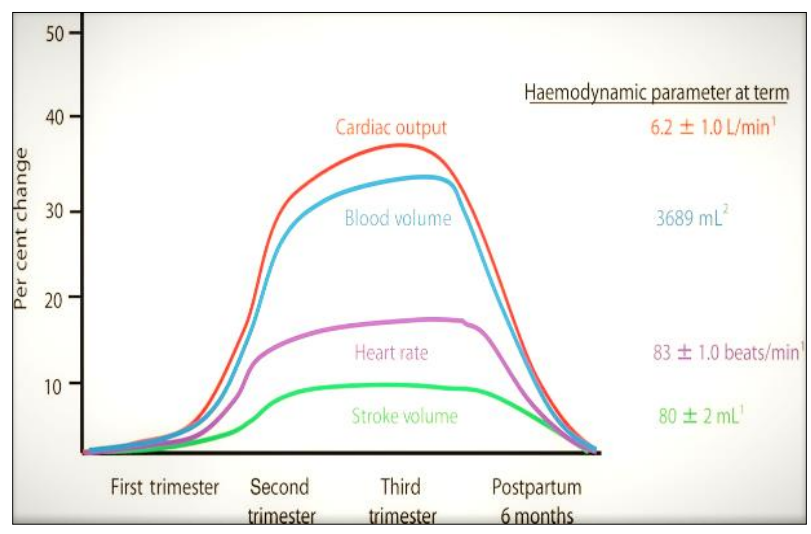

Figure 1: Physiological changes in pregnancy.

\section{Peripartum phase}

During the peripartum due to blood loss and loss of muscle tone, there is reduction in venous return(preload). In post partum, there is once again increased preload due to the release of IVC obstruction/pressure by gravid uterus or additional blood return due to contracting uterus. Increased intravenous fluids during labor (iatrogenic) may also contribute to this Preload addition. This in turn lead to raise in both systemic and pulmonary vascular resistance. All these changes may be poorly tolerated during pregnancy.

\section{Diagnostic approach of PHT in pregnancy}

Most of the symptoms of PHT in pregnancy can be very non-specific often blends with the physiological changes.

\section{Symptoms of PHT in pregnancy}

Symptoms of PHT include; dyspnea, coughs, chest pain, edema, easy fatiguability and exercise intolerance.
Additionally, patients with decompensated right heart failure present with; pedal edema, exaggerated baseline dyspnoea and syncopal attacks. Most of the symptoms deteriotes around 20 to 24 weeks.

\section{Clinical signs of PHT in pregnancy}

Clinical signs of PHT are; raised JVP, large A waves and $\mathrm{V}$ waves, palpable $\mathrm{P} 2$ in pulmonary area, parasternal heave, ejection systolic murmer in pulmonary area and pan systolic murmer in tricuspid area due to tricuspid regurgitation.

It is important to evaluate the respiratory system as these will rule out any underlying parenchymal lung disease. In addition, it is also very crucial to determine any underlying left sided valvular heart disease, left ventricular dysfunction or pulmonary venous hypertension.

\begin{tabular}{|ll|}
\hline Classification & Symptoms \\
\hline Class I & $\begin{array}{l}\text { No limitations in daily physical activities. No } \\
\text { symptoms of dyspnea with routine exertion }\end{array}$ \\
Class II & $\begin{array}{l}\text { Mild symptoms with exertion, including dyspnea and } \\
\text { fatigue. No symptoms at rest }\end{array}$ \\
Class III & $\begin{array}{l}\text { Moderate dyspnea with routine activities and } \\
\text { activities of daily living. No symptoms at rest } \\
\text { Class IV }\end{array}$ \\
& $\begin{array}{l}\text { Inability to perform even minimal activities. Signs } \\
\text { and symptoms of right heart failure may be present. } \\
\end{array}$ \\
& Dyspnea present at rest
\end{tabular}

Figure 2: WHO functional classification of PHT.

Table 1: Dana point group classification of PHT.

\begin{tabular}{|ll|}
\hline Groups & Classification \\
\hline Group 1 & Idiopathic pulmonary hypertension \\
\hline Group 2 & $\begin{array}{l}\text { Pulmonary hypertension due to left heart } \\
\text { diseases }\end{array}$ \\
\hline Group 3 & $\begin{array}{l}\text { Pulmonary hypertension due to } \\
\text { hypoxemic lung diseases/Chestwall } \\
\text { diseases/sleep apnea syndromes }\end{array}$ \\
\hline Group 4 & $\begin{array}{l}\text { Chronic thromboembolic pulmonary } \\
\text { hypertension }\end{array}$ \\
\hline Group 5 & $\begin{array}{l}\text { Pulmonary hypertension with unclear } \\
\text { and multifactorial origin }\end{array}$ \\
\hline
\end{tabular}

\section{Serological investigations}

Relevant blood investigations need to be sent to diagnose the underlying etiology and to assess the prognosis. The investigations include; full screening for rheumatological and connective tissue, disorders (RA factor, anti CCP, ANA), thyroid profile, liver function tests, renal function tests, D-dimer, HIV serology. 
Table 2: Management of pulmonary hypertension in pregnancy.

\begin{tabular}{|c|c|}
\hline Parameters & Description \\
\hline \multirow{5}{*}{ Therapeutic abortion } & Should be offered to all regardless of WHO functional class/prognostic markers. \\
\hline & First trimester is the safest period but should be performed in specialised centres. \\
\hline & $\begin{array}{l}\text { Suction and evacuation is also a safe method, if not feasible medical methods with } \\
\text { prostaglandin E1 or E2 is advised }\end{array}$ \\
\hline & Termination can be considered in the second trimester up to the point of \\
\hline & Fetal viability. After that, early delivery may be considered if clinically indicated. \\
\hline \multirow{4}{*}{ Mode of delivery } & $\begin{array}{l}\text { Vaginal delivery-Less risk of bleeding and infections but at the cost of hemodynamic and } \\
\text { physiologic changes which are detrimental to mother. }\end{array}$ \\
\hline & $\begin{array}{l}\text { Caesarean section-Preferred mode of delivery and should be used unless not available or in } \\
\text { cases of emergencies. }\end{array}$ \\
\hline & Regional anesthesia is always preferred over general anesthesia \\
\hline & Planned delivery at $34-36$ weeks \\
\hline \multirow{3}{*}{ Post partum care } & Parturition and the first postpartum week are considered as the most vulnerable period. \\
\hline & $\begin{array}{l}\text { They should be closely monitored for several days postpartum; monitoring in an intensive } \\
\text { care unit in the first few days after delivery is recommended. }\end{array}$ \\
\hline & Prophylactic heparin is usually recommended. \\
\hline
\end{tabular}

\section{Prognostic markers}

Biomarkers like BNP, troponin I, uric acid should be used in conjunction with the attending clinician's best judgment.

\section{Chest radiology}

Chest X-rays (CXR) can be performed with abdominal shield. The typical findings on CXR in pulmonary hypertension will depend on the chronicity and severity of pulmonary hypertension and these would include right ventricular hypertrophy or enlargement, right atrial enlargement and enlarged pulmonary arteries. The diameter of descending pulmonary artery greater than 16 $\mathrm{mm}$ is pathognomic for PHT. The CXR is recommended for identifying parenchymal abnormalities and could be helpful if there is suspicion of a potential pulmonary embolism.

\section{Common ECG patterns seen in patients with PHT}

ECG patterns like right axis deviation, an $\mathrm{R}$ wave/S wave ratio greater than one in lead $\mathrm{V} 1$, incomplete or complete right bundle branch block and increased $\mathrm{P}$ wave amplitude in lead II ( $\mathrm{P}$ pulmonale) due to right atrial enlargement are observed in PHT patients.

\section{Right heart catheterization and echocardiogram}

Cardiac catheterization is the gold standard investigation of choice for pulmonary hypertension.But its performed in very few cardiac centres. ${ }^{7}$ In India diagnosis largely depends on echocardiography. Right heart catheterization hasn't been used routinely in pregnancy as it is associated with risks both in the mother and fetus.

\section{Echocardiogram findings in PHT}

Common 2 D ECHO findings in patients with PHT are; tricuspid regurgitation, right atrial and ventricular hypertrophy, flattening of interventricular septum,small LV dimension, dilated pulmonary artery and pericardial effusion (poor prognostic sign).

\section{Vasoreactivity testing during right heart catherization}

inhaled nitric oxide (no) is a preferential pulmonary arterial vasodilator which is used for vasodilator testing. vasoreactivity test is positive if: mean pap decreases at least $10 \mathrm{mmhg}$ and to a value less than $40 \mathrm{mmhg}$, associated increased or unchanged cardiac output and minimally reduced or unchanged systemic blood pressure, only patients with positive vasoreactivity are given treatment trials with calcium channel blockers.

\section{Role of ultrasound}

Compression ultrasound (CUS) has a proven sensitivity of $97 \%$ and a specificity of $94 \%$ for the diagnosis of proximal deep venous thrombosis (DVT) and this should be recommended as a standard assessment in pregnancy. ${ }^{8,9}$ Ultrasound is a useful tool and is important to implement in the critical care setting, and should be used in pregnancy when there is a suspicion of DVT. Echocardiography should also be performed in these patients, as it provides direct visualization of the right ventricle and other additional abnormalities. Lung ultrasonography may help differentiate the causes of PH in critical care and minimizes radiation exposure in pregnant patients, and as a result should be integrated as an adjunct to the standard chest radiograph and CT scan. ${ }^{12,13}$ 


\section{Common causes of $P H T$ in pregnancy}

Cardiac; congenital: ASD, PDA, acquired: rheumatic heart disease with mitral stenosis, severe LV dysfunction. Respiratory; parenchymal lung diseases: post TB sequelae, interstitial lung diseases, obstructive airway diseases: asthma, bronchiectasis, chest wall abnormalities: kyphoscoliosis, sleep apnea syndromes. Vascular diseases; pulmonary thromboembolism, cteph, idiopathic pulmonary hypertension. Improved survival in pregnancy and $\mathrm{PH}$ is attributable to the new treatment modalities, including incorporation of a multidisciplinary approach. ${ }^{14-16}$ However there is no standard guidelines/approach is currently available to manage these conditions.

\section{Advice and counselling for women at the time of PAH diagnosis}

It should be made clear to women at the time of their PAH diagnosis that pregnancy is not recommended due to the high maternal and fetal risks. ${ }^{17-20}$ Proper Counselling should be given to women at the time of PAH diagnosis, together with an individual patient risk assessment, in a pulmonary hypertension centre with experience in the management of pregnancy in $\mathrm{PAH} .{ }^{21-23}$

\section{Contraceptive methods preferred}

Progestogen-only methods of contraception can be used in women with PAH. ${ }^{24}$ However, there is a moderate increase in risk of pulmonary embolism. Moreover intrauterine devices (IUD) can lead to vasovagal shock during insertion which results in hypotension and bradycardia with risk of intrauterine infections. Oestrogen-containing contraceptives also increase the risk of VTE which is preferred in patients who are already on anticoagulants. ${ }^{25}$ Barrier methods (female condoms, diaphragm, cervical cap) are safe to use in women with PAH but with unpredictable success rates. ${ }^{17,18}$ Surgical methods like tubal ligation may be considered in selected patients. Dual contraception is indicated in patients who are on bosentan, due to the drug interactions with progesterone based contraceptives.

\section{Artificial reproductive techniques in PHT patients}

Both in vitro fertilisation and harvesting of eggs are not advised in PAH. Although there are no data for in vitro fertilisation in PAH, common serious adverse events in healthy individuals include ovarian hyperstimulation and risks of VTE, which would have potential detrimental effects on women with PAH. For a woman with PAH who wishes to become pregnant, genetic screening and counselling should be considered. ${ }^{26}$

If the patient has heritable $\mathrm{PAH}$ and a mutation in a PAHassociated gene has been identified, the risk of the child inheriting the mutation and developing PAH should be discussed. It is important to consider disease aetiology in women with PAH who are pregnant, or who plan to become pregnant, as this may affect treatment strategies not just for PAH but also for the underlying disease. For example, patients with PAH associated with connective tissue disease may be receiving treatment with immunosuppressants, which may be contraindicated in pregnancy. If a woman with known PHT becomes pregnant, counselling should be given for therapeutic abortion. If they are willing for therapeutic abortion, it should be done before 22 weeks of gestation. ${ }^{25}$ Women with PHT should be referred to a tertiary care centre who is having experience in managing these cases with multidisciplinary team which includes cardiologist, pulmonologists, critical care physicians, obstreticians and neonatologists. In addition, a pregnancy care plan should be detailed from early on, including timing and mode of delivery for the woman with $\mathrm{PAH}^{7}$ Regular close monitoring with follow up is advised and early hospitalisation before delivery to optimise the therapy for PHT. Follow up include monitoring of fetal growth with ultrasound with doppler study and pulmonary hemodynamics with the help of 2D ECHO. Hospitalisation of women with PAH in the second trimester is sometimes appropriate due to the increased risk of premature labour and haemodynamic complications. ${ }^{17,21}$

\section{PAH specific therapies}

All women with PAH should be initiated on PAH specific therapies (prostanoids, CCBs, phosphodiesterase inhibitors) except endothelin receptor blockers as it is teratogenic.

Calcium channel blockers; these drugs are the preferred for responders to inhaled NO. Most commonly used regimen are high dose nifedipine $(200 \mathrm{mg})$, diltiazem (700 mg). Epoprostenol (pg i2); epoprostenol is considered as the first line therapy for patients with poor WHO functional class. It is safe in all trimesters without any adverse fetal outcomes reported. Worsening of PHT may occur occasionally with the therapy. At present it is not available in India. Inhaled iloprost; In NYHA II-III, Inhaled iloprost is successfully used in PHT patients with no congenital anomalies. Phospho diesterase inhibitors; sildenafil: it acts by reduction in cGMP breakdown and increases sensitivity to NO. No adverse fetal outcomes are noted in the clinical studies. The usual dosage is 20 $\mathrm{mg}$ thrice daily. Common adverse effects of phosphodiesterase inhibitors include flushing, headache, giddiness and hypotension. Tadalafil: it also acts by reduction in cGMP breakdown and increases sensitivity to nitric oxide.

Endothelin receptor antagonists (bosentan, ambrisentan, macitentan); endothelin plays a potent role in fetal development. It is contraindicated in pregnancy as it is teratogenic. Inhaled nitric oxide: inhaled NO is used in pulmonary vasoreactivity test to assess the response to calcium channel blockers. It is used in treatment of acute 
pulmonary hypertension in the peripartum period. Oxygen: moist oxygen is given to maintain $\mathrm{Pao} 2$ above 70 and also to improve air hunger and hypoxemia. Diuretics: It relieves the raised intravascular volume and decreases hepatic congestion. Furosemide is considered safe during pregnancy. Spironolactone causes fetal androgenic effects should be avoided.

\section{Role of anticoagulants}

Pregnancy is a hypercoagulable state. Lifelong anticoagulation in Idiopathic pulmonary hypertension is needed to reduce the risk of in situ thrombosis and thromboembolism. Risk of thromboembolism is increased especially during the first postpartum week and during operative surgeries which is a leading cause of maternal death. Vitamin $\mathrm{K}$ antagonists (warfarin) are contraindicated in pregnancy (craniofacial malformations). Heparin is safe during pregnancy. Prostacyclins have short lived antiplatelet effect, although these agents should not be stopped during labour.

\section{Treatment of pregnancy related manifestations}

Activation of coagulation cascade due to decrease in protein $\mathrm{C}$ and protein and antithrombin resistance. ${ }^{27}$ Vitamin $\mathrm{K}$ antagonists are contraindicated in the first trimester of pregnancy due to their potential fetal craniofacial abnormalities (chondrodyplasia punctuata). ${ }^{25}$ Further use of warfarin leads to bleeding complications, spontaneous abortions and CNS anomalies. Heparin and low molecular weight heparin (LMWH) are recommended in $\mathrm{PAH}$.

Fluid restriction (less than 1.2-1.4 litres per day) and salt restriction to reduce the preload. They should be adviced to avoid lying on their backs to prevent compression of the inferior vena cava by gravid uterus.It is crucial to manage hyperemesis gravidarum because it results in fluid and electrolyte imbalances and reduce the efficacy of oral medications during the pregnancy.

\section{Preferred mode of delivery in PHT}

Normal vaginal delivery is advantageous as it is associated with minimal blood loss, less risk of embolism, infectious complications and less incidence of abrupt hemodynamic alterations when compared with Caesarean section. ${ }^{28,29}$ However, a protracted labour is detrimental with adverse hemodynamic changes which affects both mother and fetus. It can precipitate hypoxia, hypercapnia and acidosis. ${ }^{30}$ Hence all the pregnant mother with PHT planned for vaginal delivery needs careful monitoring. Women should be monitored by electrocardiogram at all times throughout labour with ECG, pulse oximetry and CVP monitoring in patients with right heart failure (Table 3).
Table 3: Management protocols for PHT.

\begin{tabular}{|c|c|}
\hline Trimester & Management protocol \\
\hline \multirow{5}{*}{ First trimester } & Stop ETRA/warfarin/coumorin \\
\hline & $\begin{array}{l}\text { Refer to high risk obstetric unit } \\
\text { experienced in PHT care }\end{array}$ \\
\hline & $\begin{array}{l}\text { Monthly follow up with } 2 \text { D } \\
\text { Echo, BNP, } 6 \text { minute walk test }\end{array}$ \\
\hline & $\begin{array}{l}\text { Start low molecular weight } \\
\text { heparin (LMWH) if patient is in } \\
\text { bed rest/for all patients. }\end{array}$ \\
\hline & $\begin{array}{l}\text { Recommend therapeutic } \\
\text { abortion if any signs of right } \\
\text { heart failure. }\end{array}$ \\
\hline \multirow{4}{*}{ Second trimester } & $\begin{array}{l}\text { Multidisciplinary team } \\
\text { approach, }\end{array}$ \\
\hline & $\begin{array}{l}\text { Monthly follow up with 2D } \\
\text { Echo,BNP, } 6 \text { min walk test. }\end{array}$ \\
\hline & $\begin{array}{l}\text { Start low molecular weight } \\
\text { heparin }(\mathrm{LMWH}) \text { if patient is in } \\
\text { bed rest/in patient. }\end{array}$ \\
\hline & Optimise PAH therapy. \\
\hline \multirow{6}{*}{ Third trimester } & Multidisciplinary approach \\
\hline & $\begin{array}{l}\text { Weekly visit with } 2 \text { DEcho, } \\
\text { BNP, } 6 \text { min walk test }\end{array}$ \\
\hline & Optimise PAH therapy. \\
\hline & $\begin{array}{l}\text { Start low molecular weight } \\
\text { heparin }(\mathrm{LMWH}) \text { if patient is in } \\
\text { bed rest/In patient. }\end{array}$ \\
\hline & Elective caesarean section. \\
\hline & $\begin{array}{l}\text { Close post operative ICU } \\
\text { monitoring. }\end{array}$ \\
\hline
\end{tabular}

Planned caesarean delivery is more comfortable and advantageous in avoiding a Protracted labour. Caesarean sections are preferred to be done under spinal anesthesia as general anaesthesia increases the risk of complications in women with PHT. ${ }^{31,32}$ Optimal timing would be 32-36 weeks of gestation.

It is important that the underlying PAH is well controlled first whatever the mode of delivery. Many centres in western countries prefer to use intravenous epoprsotenol in women with PHT just prior to delivery. But in India it is not available for use. Even if women have well compensated PAH prior to delivery, acute deterioration and death can occur post-partum; therefore, treatment with intravenous epoprostenol is continued at some centres for some time after delivery.

\section{Postnatal care for mother and neonate}

Post-partum care and monitoring of women with pulmonary hypertension is crucial as this period carries the highest morbidity and mortality. ${ }^{33}$ Most of the deaths were documented within one month after delivery predominantly due to right ventricular failure. ${ }^{34,35}$ Inhaled NO, prostanoids and inhaled iloprost are useful to reduce the risk of postpartum right ventricular failure in these 
patients. Patients with RV decompensation with hypotension may also require vasopressors and inotrophic agents. Oxytocin is used to prevent bleeding complications after caesarean section. ${ }^{36}$ But use of oxytocin sometimes causes hypotension and reflex tachycardia which in turn aggravates raise in pulmonary artery pressure. ${ }^{37,38}$

\section{Lactation}

In patients who are on vasodilators for PHT, breastfeeding is not usually recommended as it may be excreted in breast milk and a negative effect of prolactin on the myocardium cannot be excluded in these patients. ${ }^{39-41}$ Long term follow up is often needed in patients with PAH after pregnancy. As delivery is planned usually in 32 to 36 weeks in patients with severe PHT, there is a high chance that babies born are premature and may require special care in premature baby unit (Table 2). ${ }^{42,43}$

\section{CONCLUSION}

$\mathrm{PH}$ in pregnancy is one of the high-risk medical conditions. Efforts should be made to educate patients and promote safe contraceptive methods. Planning for delivery is a process that requires a team approach. We must pay attention to the impact of $\mathrm{PH}$ drugs on pregnancy. Patients in the post-partum period are most vulnerable to death and should be closely monitored in an ICU setting.

Funding: No funding sources Conflict of interest: None declared

Ethical approval: Not required

\section{REFERENCES}

1. Galiè N, Hoeper MM, Humbert M. Guidelines for the diagnosis and treatment of pulmonary hypertension. Eur Heart J. 2009;30:2493-537.

2. Bassily-Marcus AM, Yuan C, Oropello J, Manasia A, Kohli-Seth R, Benjamin E. Pulmonary hypertension in pregnancy: Critical care management. Pulm Med. 2012;2012:709407

3. Weiss BM, Zemp L, Seifert B, Hess OM. Outcome of pulmonary vascular disease in pregnancy: A systematic overview from 1978 through 1996. J Am Coll Cardiol. 1998;31:1650-7.

4. Smith JS, Mueller J, Daniels CJ. Pulmonary arterial hypertension in the setting of pregnancy: A case series and standard treatment approach. Lung. 2012;190:155-60.

5. La Vecchia L, Ottani F, Favero L, Spadaro GL, Rubboli A, Boanno C, et al. Increased cardiac troponin $\mathrm{i}$ on admission predicts in-hospital mortality in acute pulmonary embolism. Heart. 2004;90:633-7.

6. Ghofrani HA, Wilkins MW, Rich S. Uncertainties in the diagnosis and treatment of pulmonary arterial hypertension. Circulation. 2008;118:1195-201.
7. Marik PE, Plante LA. Venous thromboembolic disease and pregnancy. N Engl J Med. 2008;359: 2025-33.

8. Burgazli KM, Bilgin M, Kavukcu E, Altay MM, Ozkan HT, Coskun U, et al. Diagnosis and treatment of deep-vein thrombosis and approach to venous thromboembolism in obstetrics and gynecology. J Turk Ger Gynecol Assoc. 2011;12:168-75.

9. Stone SE, Morris TA. Pulmonary embolism during and after pregnancy. Crit Care Med. 2005;33:S294300 .

10. Stone SE, Morris TA. Pulmonary embolism and pregnancy. Crit Care Clin. 2004;20:661-77.

11. Kajimoto K, Madeen K, Nakayama T, Tsudo H, Kuroda T, Abe T. Rapid evaluation by lung-cardiacinferior vena cava (lci) integrated ultrasound for differentiating heart failure from pulmonary disease as the cause of acute dyspnea in the emergency setting. Cardiovasc Ultrasound. 2012;10:49.

12. Cardinale L, Volpicelli G, Binello F, Garofalo G, Priola SM, Veltri A, et al. Clinical application of lung ultrasound in patients with acute dyspnea: Differential diagnosis between cardiogenic and pulmonary causes. Radiol Med. 2009;114:1053-64.

13. McMillan E, Martin WL, Waugh J, Rushton I, Lewis M, Clutton-Brock T, et al. Management of pregnancy in women with pulmonary hypertension secondary to sle and anti-phospholipid syndrome. Lupus. 2002; 11:392-8.

14. Bedard E, Dimopoulos K, Gatzoulis MA. Has there been any progress made on pregnancy outcomes among women with pulmonary arterial hypertension? Eur Heart J. 2009;30:256-65.

15. Kiely DG, Condliffe R, Webster V, Mills GH, Wrench I, Gandhi SV, et al. Improved survival in pregnancy and pulmonary hypertension using a multiprofessional approach. BJOG. 2010;117:56574.

16. Galiè N, Humbert M, Vachiery JL. 2015 ESC/ERS Guidelines for the diagnosis and treatment of pulmonary hypertension. Eur Heart J. 2016;37:67119.

17. Hemnes AR, Kiely DG, Cockrill BA. Statement on pregnancy in pulmonary hypertension from the pulmonary vascular research institute. Pulm Circ. 2015;5:435-65.

18. Hsu CH, Gomberg-Maitland M, Glassner C. The management of pregnancy and pregnancy-related medical conditions in pulmonary arterial hypertension patients. Int J Clin Pract Suppl. 2011; 175:6-14.

19. Olsson KM, Jais X. Birth control and pregnancy management in pulmonary hypertension. Semin Respir Crit Care Med. 2013;34:681-8.

20. Thorne S, Nelson-Piercy C, MacGregor A. Pregnancy and contraception in heart disease and pulmonary arterial hypertension. J Fam Plann Reprod Health Care. 2006;32:75-81.

21. Mantha S, Karp R, Raghavan V. Assessing the risk of venous thromboembolic events in women taking 
progestin-only contraception: a meta-analysis. BMJ. 2012;345:e4944.

22. Hemnes AR, Kiely DG, Cockrill BA. Statement on pregnancy in pulmonary hypertension from the Pulmonary Vascular Research Institute. Pulm Circ. 2015;5:435-65.

23. Austin ED, Loyd JE, Phillips JA. Heritable pulmonary arterial hypertension. In: Pagon RA, Adam MP, Ardinger HH, eds. Seattle: University of Washington publication; 2002.

24. Liu S, Liston RM, Joseph KS. Maternal mortality and severe morbidity associated with low-risk planned cesarean delivery versus planned vaginal delivery at term. CMAJ. 2007;176: 455-60.

25. Uebing A, Steer PJ, Yentis SM. Pregnancy and congenital heart disease. BMJ. 2006;332: 401-6.

26. Warnes CA. Pregnancy and pulmonary hypertension. Int J Cardiol. 2004;97:11-3.

27. Jais X, Olsson KM, Barbera JA. Pregnancy outcomes in pulmonary arterial hypertension in the modern management era. Eur Respir J. 2012;40:8815.

28. Bedard E, Dimopoulos K, Gatzoulis MA. Has there been any progress made on pregnancy outcomes among women with pulmonary arterial hypertension?. Eur Heart J. 2009;30:256-65.

29. Bonnin M, Mercier FJ, Sitbon O. Severe pulmonary hypertension during pregnancy: mode of delivery and anesthetic management of 15 consecutive cases. Anesthesiol. 2005;102:1133-7.

30. Madden BP. Pulmonary hypertension and pregnancy. Int J Obstet Anesth. 2009;18:156-64.

31. Louis ED, Mayer SA, Rowland LP. Merrit's Neurology. 13th Ed. Netherlands: Wolters Kluwer; 2015:1043.

32. Yamaguchi ET, Cardoso MM, Torres ML. Oxytocin in cesarean sections: what is the best way to use it? Rev Bras Anestesiol. 2007;57:324-50.

33. O'Hare R, McLoughlin C, Milligan K. Anaesthesia for caesarean section in the presence of severe primary pulmonary hypertension. $\mathrm{Br} \mathrm{J}$ Anaesth. 1998;81:790-2.
34. Albackr HB, Aldakhil LO, Ahamd A. Primary pulmonary hypertension during pregnancy: a case report. J Saudi Heart Assoc. 2013;25:219-23.

35. Terek D, Kayikcioglu M, Kultursay H, . Pulmonary arterial hypertension and pregnancy. J Res Med Sci. 2013;18:73-6.

36. Madden BP. Pulmonary hypertension and pregnancy. Int J Obstet Anesth. 2009;18:156-64.

37. Hilfiker-Kleiner D, Struman I, Hoch M. 16-kDa prolactin and bromocriptine in postpartum cardiomyopathy. Curr Heart Fail Rep. 2012;9:17482.

38. Elliot CA, Stewart P, Webster VJ. The use of iloprost in early pregnancy in patients with pulmonary arterial hypertension. Eur Respir J. 2005; 26:168-73.

39. Kiely DG, Condliffe R, Webster V. Improved survival in pregnancy and pulmonary hypertension using a multiprofessional approach. BJOG. 2010; 117:565-74.

40. Bildirici I, Shumway JB. Intravenous and inhaled epoprostenol for primary pulmonary hypertension during pregnancy and delivery. Obstet Gynecol. 2004; 103:1102-5.

41. Avdalovic M, Sandrock C, Hoso A. Epoprostenol in pregnant patients with secondary pulmonary hypertension: two case reports and a review of the literature. Treat Respir Med. 2004;3:29-34.

42. Stewart R, Tuazon D, Olson G. Pregnancy and primary pulmonary hypertension: successful outcome with epoprostenol therapy. Chest. 2001;119:973-5.

43. Lacassie HJ, Germain AM, Valdes G. Management of Eisenmenger syndrome in pregnancy with sildenafil and L-arginine. Obstet Gyneco.1 2004;103:1118-20.

Cite this article as: Durga K, Yuvarajan S, Praveen R, Selvam AM, Yashoda, Karthiga V. Pulmonary hypertension in pregnancy. Int J Reprod Contracept Obstet Gynecol 2021;10:1259-65. 